\title{
Transformation of a female gender identity in South Korea
}

\author{
Nataliia Andreevna Bunaeva $^{1 *}$, Bairma Sergeevna Sosorova ${ }^{1}$, Aiuna Aleksandrovna Orsoeva ${ }^{1}$ \\ ${ }^{1}$ Irkutsk State University, Department of Oriental and Regional Studies of the Asia-Pacific Region, 664003, Irkutsk, Karl Marx \\ Street 1, Russia
}

\begin{abstract}
The goal of this article is to determine a female gender identity in South Korea in the period of traditional society and its transformation till the present time. Identification is carried out on the basis of historical analysis of the most important aspects of cultural and social life. A female gender identity formation is closely related to basic Korean social constituencies such as mentality, national character, state gender policy, values and religious ideas that have an impact on differentiation of gender roles, position and status. It is concluded that gender relationship is an indicator of the civility level. The mechanisms of particular gender sequence formation in the context of different historical periods contribute to uncovering gender relationship peculiarities and general patterns of a Korean female identity transformation.
\end{abstract}

\section{Introduction}

Lately the Olympic Games are mostly associated with scandals than sports itself and 2020 Games in Tokyo were not an exception. Korean national team archer An San was at the center "of a feminist scandal". Despite two Olympic golds anti-feminists focused on her hair mostly, the 20-year-old female archer is being criticized for the length of her hair. A predominantly male online community labeled An as a feminist, posted "Women who attend women's universities and have a short cut are 90 percent likely to be feminist". In Korea, "short cut" refers to short, conventionally masculine hairstyles, usually when worn by women. Some women being afraid of social accusation wear long hair, while others have short cuts on purpose. This scandal exemplifies the fact of traditional strict beauty cult existence and modern expression of a new female identity of a Korean woman without long hair, an "idol" make-up and plastic surgery.

Such a controversial position and status of a woman in Korea generated a scientific interest in researching the issue.

\section{Discussion}

The studying of the female identity in South Korea is associated with approaches to determining position, status, female character traits and their transformation starting from traditional societies to modern one.

During the ruling of the Silla Dynasty (57BC-935 AD) women had relatively high social status. The women's position was based on shamanism and Buddhism. Thus, religious tradition and decent bloodline were a more significant criterion than gender was. In contrast to later periods, women in Silla Kingdom according to "Three kingdom chronicles" were allowed to move freely around the Kingdom. Lower and middle class women often worked in the agricultural spheres and paid taxes till 60 as well as men. While men joined the Army women became the head of the family controlling finances of the household. The sex of the heir became not so important as it was earlier and men could not divorce their spouses if they did not procreate male offsprings. The period was characterized with the lack of social differences between genders. Marriage was considered as partnership of equal men and women. Children could inherit mother's surname as she was the person who continued the family line. Sisters had equal rights with their brothers in property and slaves' inheritance. It was natural behavior for a woman to get married for the second time. Taking all these reasons into account this period could be called to some extent the era of matriarchy. Aristocratic women played a great role in governmental structures and judicial sphere, and even some of them could run the country.

The Goryeo dynasty continued the tradition of the Silla dynasty. Children received wealth from their parents equally, and it was not uncommon for women to inherit their own homes. In many cases, grooms stayed with the bride's family after their marriage till the age of 30. During this time, a child's status was determined by the family of both parents [1].

The Goryeo dynasty (918 AD-1392 AD) initially took a fairly liberal stance on women, but the growing influence of Confucianism ultimately caused the status of women to increasing decline. According to the records of the Chinese traveler Xu Jing (1091-1153), men and women interacted freely, with no laws specifically prohibiting male and female social exchange. Women could also inherit property, and inheritances were split equally between sons and daughters. If a woman died without children, her possessions could be passed onto her siblings, as opposed to her husband. The practice of

* Corresponding author: nataly-1980@yandex.ru 
allowing women to inherit is indicative of the relative respect females were regarded with; like men, they were endowed with enough trust to own property. Marriage, however, was expected of all respectable Goryeo females, and single women were generally looked down upon. While a dowry was desirable, young brides were not required to bring anything but a wardrobe and the household supplies they would use. Although the bride's family was expected to pay the substantial cost of the wedding feast and ceremonies, females were generally not regarded as burdens who robbed their families of wealth, but as vital members of their natal families. Ideally, widowed women remained chaste, but many remarried, and in some cases, a widow was permitted to bring her deceased husband's land and wealth as her dowry. Accordingly, widows of soldiers who died in battle were given a government land grant that would support their family, but were expected to return it in the case of remarriage. The Silla and Goryeo treatment of women should not be mistaken to signify that females enjoyed complete freedom or equality; women continued to be under the jurisdiction of men and subject to strict behavioral expectations. As time progressed, records show increasing numbers of women being confined to the home and restricted from outside labor. Wealthy women began to be raised upon the ideals of the Yochik, a Koryo book that taught women to uphold filial and submissive behavior. Confucianism, which increased in popularity throughout the Goryeo period, encouraged the strengthening of mutually exclusive gender roles, and the status of women subsequently declined throughout the dynasty.

The strict social and gender hierarchy principle of the Confucian ideology continued making a great impact on labor and family ethics formation in South Korea during the Joseon Dynasty (1392-1910). The social and family women's place and role in traditional Korea of that period were defined and regulated by the Doctrine for more than 5 centuries. Relationships in society were founded on the basis of subordination to a universal hierarchy, which means a definite place and role for every person, keeping which leads to the maintenance of universal harmony. In the postulate of Samganorun, "three principles and five relations" were spelled out. According to these three principles the relationship between a ruler and a vassal, parents and children and spouses were built. Five relationships regulated the norms of how to treat the ruler, parents, elders, friends and spouses [2].

The relationship between spouses was one of the three most important principles of building a correct society and an ideal state. Harmony and peace in the family were believed to ensure the prosperity of the country; therefore, often in traditional Korean novels, turmoil in the state was the consequence of the violation of harmony in the family. According to the Pubi-byol postulate, a man and a woman are unequal beings, since their essence is opposite. A man is an active and dominant being, and a woman is passive and must obey the will of a man. A certain set of activities related to the organization of domestic life was considered, in which a woman fulfilled her function in maintaining harmony in the family and the state. Girls were brought up to obey men unquestioningly: in the house of her parents, they obeyed their father, after marriage - their husbands, in the event of the death of the latter, to the eldest son. The wife was obliged to remain faithful to her husband even after his death, which meant that remarriage was impossible.

The higher the class a woman belonged to, the more reclusive lifestyle she led and the stricter the control over the observance of the rules of conduct was. Division of the living space of a woman and a man was strict, there were specially designated rooms located at the back of the house called anchae where the Yangban estate aristocratic women spent most of their lives. Women were not allowed to show themselves to men who were not family members, therefore, if they had to leave the house, they had to wear a special cape and use a closed palanquin. For breaking the rules, the law provided one hundred blows with a stick as a punishment. Only peasant women who worked in the field on an equal basis with their husbands were an exception [3].

As for classical education it was inaccessible for most women. Only men could be involved in intellectual activities in Joseon. The Hangeul (Korean alphabet) was taught to women in order to educate them for the required moral qualities and explain the responsibilities associated with organizing family life and rituals, as well as the rules of conducting the house of a father and husband, prescribed in instructions for noble ladies. Hanmun (a modified Chinese language) was for men to read and write. Reading other books, especially engaging in literary creativity, was forbidden as submissiveness was required from aristocratic women and they had to lead an inconspicuous life [3]. Sisohwa (literature, painting or calligraphy) was considered obscene. Kisaeng - Korean courtesans - were composing poetry and drawing in the presence of men. Rarely, but it happened that a girl from noble families still managed to get a classical education and history has preserved information about several aristocrats who became famous for their artistic talents, the most famous of whom were the artist Shin Saimdan and the poet Ho Nansorkhon.

At the end of the 17th century the system of Confucian values cracked after a series of invasions by foreign invaders. Thus, the rulers of Joseon faced the need to strengthen the positions of state ideology and the statesmen created kassa poems - "melodious stanzas" designed to convey Confucian morality and rules of behavior to the people. As for women, in the 18th century the genre of kubankas was formed ("melodious stanzas of the female half of the house") to instruct women in their responsibilities to maintain order and harmony in the house and ensure a comfortable existence for men.

Gradually, women began to write poems on their own. It was connected with the strengthening of the role of women in noble houses by imposing on them the responsibility of planning the family budget [4]. The main themes of kyubankas were love, the hardships of the female life, personal feelings and separation (with a loved one or with parents after marriage). 
Unlike most aristocratic women, kisaeng courtesans could receive a classical education. They could paint, write poetry and play musical instruments. Being worthy interlocutors of educated men, they were called kheohwa - lit ("A flower that understands language"). In spite of the fact that kisaeng works depended on the customer's order in the choice of subject, i.e. from men, they had a right to depict the four noble plants - bamboo, orchids, mehwa plums and chrysanthemums - that symbolized the moral qualities of a true Confucian. This choice of subject equates Chukkhyan's painting with the work of contemporary male artists. The interest in the biography and creativity of the kisaeng is explained by changes in social thought at the turn of the 18th and 19th centuries.

The establishment of the system of public education for women during the years of the Japanese occupation of Korea (1910-1945) became one of the main factors in changing the perception of the social responsibilities of Korean women. Gradually, the educated Korean woman began to embody a new type of woman, free from traditional norms of behavior based on neo-Confucian ethics. With the transformation of Korea into a colony (1910), the General Government issued a decree on education in 1911, which proposed the creation of a system of state comprehensive schools of two levels: primary (4 years) and senior (4 years) in comparison with a three-year-course of study in 1908. Especially for girls, a senior general education school was created (yoja kodin pothon hakkyo), where they studied for another three years. Girls over 12 years old were admitted to such schools. They studied the following subjects: morality, Korean and Japanese, hanmun, history / geography, arithmetic, natural history, household, calligraphy, drawing, music, sewing [5]. Graduation from such a school gave them an opportunity to enter a higher educational institution.

However, such a system contributed to the formation in the public consciousness of a new image of an ideal woman as a "wise mother and a good wife" (hyongmoyancho). The educational goals of women were rather limited: it was aimed at acquiring basic knowledge in the field of writing, natural science and culture, and to a greater extent - at developing the skills of rational housekeeping.

The "new women" (shinoja) were the first women of aristocratic descent in Korean history who publicly questioned the truth of the Confucian postulate of pubibyol. New ideas such as free love and the right of a woman to independently choose a spouse were expressed in women's magazines "Yojage" ("Women's World", 1917-1920), "Sinyoson" ("New female gender", 1923-1934), "Sinyoja" ("New women", 1920).

The Korean society of the colonial era was not ready to adequately assess the "new women" ideas about economic independence and independence from men. This movement was treated as outsiders both in the cultural and political life of Korea in the 1920s and 1940s.

The reasons for the negative perception of "new women" in the Korean cultural environment are rooted in the peculiarities of colonial society, which existed in the first half of the 20th century. Japanese colonialism played a negative role in maintaining gender inequality and in maintaining traditional family values. The colonial policy of the Japanese government - generally in education, economy and politics - was based on the principles of hierarchy and social inequality. Not having equal rights with the Japanese, Koreans experienced discrimination in education, employment and culture. As a result, the scale of inequality became total, covering the smallest aspects of human life.

The 1920s were the heyday of the women's social movement and a new starting point in the development of the social and national identity of Korean women. They participated in the movement for the return of the national debt (kukche posan undong). Then women joined a large-scale national fundraising movement for the Korean government and took part in the uprising against Japanese colonialism.

Within the framework of the socialist concept, the liberation of women was thought of as class liberation. The elimination of early marriages and the institution of concubines, the right to a second marriage, the expansion of opportunities for women to work - all these innovations, according to women-socialists, were not enough to achieve full equality with men. Genuine liberation of women from the burden of traditional duties and values, the achievement of equal economic and political opportunities with men were only possible in the event of a "class revolution" and the establishment of a socialist system.

In January 1925, in Seoul, the General Women's Youth Union (Yeoja chonnyon chong dongmen) was established, branches of which were expanded throughout Korea. The activities of the Union were aimed at working among the masses - educating women and "awakening" class consciousness in them. The performance of the Union and other women's socialist groups was comparatively low because such work was carried out in cities, and not in the countryside, where the vast majority of the population lived at that time. According to historian Sung Hee Lee, the leaders of the movement showed little interest in the real difficulties of women living in villages [5]. In 1927 the Society of Friends of Mugunkhwa (Kunukhwe) was created uniting the activists of the nationalist and socialist movements. In their program they put forward the following requirements: 1) elimination of any forms of social and legal discrimination against women; 2) elimination of all feudal traditions and beliefs; 3) prohibition of early marriages and the provision of freedom of marriage and freedom of divorce; 4) prohibition of "sexual slavery" and legal prostitution; 5) protection of the economic rights of peasant wives; 6) elimination of the income gap between working men and women and the provision of paid parental leave ( 4 weeks before delivery and 6 weeks after delivery); 7) ban on dangerous, night work for women and youth; 8) elimination of gender discrimination in the assessment of knowledge in educational institutions and expansion of female primary education; 9) freedom of the press, speech, assembly; 10) providing financial assistance to workers during the period of illness and support for children's educational 
institutions; and others [5]. In 1931 the organization collapsed due to arrests and police terror.

Women, in one way or another, continued to participate in the public life of Korea even in the harsh conditions of the militaristic colonial regime, which aimed at "re-educating" the Korean nation, or its complete japanization.

In spite of the fact that the first half of the $\mathrm{XX}$ century was a period of increasing social activity of women in various spheres of public life - political, cultural and economic, the colonial regime did not bring any significant changes in terms of building their everyday life and ideas about their place in society. The era of the colony outlined the problems to be solved at a new stage in the development of Korean society.

In 1948 Korea became a republic. Consequently, it was a new point in the development of women's rights. In addition, the rejection of Confucianism as a state ideology created a new socio-political climate in the country: by all formal criteria, the Republic of Korea was a democratic state that guaranteed equality of rights for its citizens in all spheres of public life. Eliminating traditional ideas of natural inequality between men and women turned out to be rather complicated.

In the $1950 \mathrm{~s}$ there were about 20 women's organizations that were not influential players on the political scene, they helped to mobilize the consciousness of women for the implementation of specific government tasks. In the 1960-1970s rural women were involved in active social activities to contribute to the implementation of the state program for the development of the village.

The Catholic Church played a great role in eradicating discrimination against women, eliminating domestic violence, expanding employment opportunities, raising the level of education and creating favorable conditions for raising children.

In the 1970s the main priority for men before getting married was stability at work while for women the demand changed. Parents made daughters graduate from universities not to work but to see them married well. Studying at pro-American universities women learned about feminist ideas of gender equality [6]. Women labor experience was minimal as they were fired immediately after getting married. Thus, they were not considered as the main labor force.

By the mid-1980s, higher education was no longer considered the privilege of men. Women started to occupy the positions in this sphere in the absolute minority (20-30\%) [7].

Since the mid-1990s, there has been a steady but low increase in the number of women in political and judicial spheres. Thus, the political sphere was still a monopoly field for men: women participate in "big politics" to the extent that it is allowed by the "male majority". As for marriage and family life, the attitude of Korean women changed as well. Marriage became a contract between two people with their own duties and responsibilities defined by the tradition where a husband had to provide the family properly. This kind of family relationships led to the increasing number of divorces initiators of which were mostly women. It was essential for Korean women to make the right choice of a husband paying attention to his health, background and career perspectives but not to love or feelings. Even in the modern world, marriage continues to be considered an obligatory and inevitable part of life of any Korean. Moreover, there is "the institution" of marriage mediators whose purpose is preserving traditions of clan veneration. Consequently, this attitude to a marriage resulted in practical lack of bachelors (33-34) and spinsters (29-30). Refusal of Korean women to live together with husband's parents, abortion legalization, the increasing number of divorces caused the creating a new type of a modern Korean family - a nuclear one with few children where both spouses make a career. In addition, young Koreans have a tendency not to get married at all.

According to the Korean National Statistical Office, in $200251.6 \%$ of married women were employed, it was a historical milestone in women's employment. By 2013 the level of women employment was only $56 \%$. Such a situation is connected with not only the traditions of Confucianism but with the problems that women have when willing to continue professional career after getting married or giving birth to a child. The major obstacles relate to untrustworthy care in kindergartens, the gap in the wage rates $(37,4 \%$ according to the Organization for Economic Cooperation and Development in 2014), colleagues' negative attitude to pregnancy and motherhood and sexual harassment. The Ministry of Gender Equality and Family develops a project "The main plan of gender equality policy" aimed at improving women's position and attitude towards them by creating real gender partnership. Moreover, the Ministry tries to change the attitude towards women in the judicial system in which male sexual criminals stay unpunished as criminal record influences the future employment. Song Ran-hee, secretary general of the Korea Women's Hotline, a non-profit group that provides counseling and shelter services to women in need, says that though no official statistics are kept on this. Her group's research shows that about one woman is murdered by an intimate partner or ex-partner every three days in Korea. One woman is murdered by an intimate partner or ex-partner every three days in Korea [8].

Appearance of online activism by Megalia has been, to some extent, a response to the reality of increasing violence against women and the story of its creation shows how extensive and bitter tensions in Korea have become. The group has its roots in the May 2015 outbreak in Korea of Middle East Respiratory Syndrome, or MERS, a disease that was first identified in Saudi Arabia in 2012. The outbreak was linked to a Korean man returning from the Middle East. However, after two Korean women who apparently contracted the disease while traveling on a flight from Seoul to Hong Kong for a holiday refused to be quarantined in Hong Kong, critics on a popular Korean message board called DC Inside (similar to Reddit in the US) viciously attacked them, calling them selfish and saying they damaged Korea's reputation abroad. While the women were later led into quarantine, the online chatter devolved, with many calling them "Kimchi bitches," for women who are 
obsessed with wealth, and "doenjang girl" or "bean paste girl," a reference to young.

Angry at the MERS accusations, some women responded by posting messages on the same message board, adopting a controversial practice female activists call "mirroring," or mimicking the language men use against women. They called men "kimchi men," among other epithets, and mocked them for having " $6.9 \mathrm{~cm}$ penises" Megalian.com. These women broke out of DC Inside to create their own site and Megalian.com was born. It was an instant provocation: the logo of the site shows a hand with the thumb and index finger close together. It reflects its satiric nature, heavily influenced by the feminist novel Egalia's Daughters: A Satire of the Sexes by Norwegian author Gerd Brantenberg. In the influential feminist oeuvre, Brantenberg narrates a world where gender roles are entirely reversed linguistically (women are called 'wim' and men 'menwim', making the man the suffix), socially (women are by default given the upper hand at the home and in society due to their power to give birth), and sexually (men are at constant risk of sexual assault; the blame is entirely theirs and not of their assailant). The logo alludes to South Korean society's - notably men's - highly judgmental attitude towards women's physical appearance and mirrors the male obsession with women's sexuality and physical attributes by mocking the size of South Korean men's penises - "they are just not good enough". Many, including some feminists, say Megalia's tactics have opened the group up to accusations of misandry, and exacerbate the gender wars. Controversial Megalia beliefs and actions include outing gay men who are married to women. Megalia members are referred to by men online as "crazy bitches" who are "completely dedicated to hating the opposite gender," and some men even compare to Megalia to ISIL. But members of the group are embracing the upheaval. "Before that, feminism was very boring and academic in Korea," says a Megalia activist, a graduate of the elite Ewha Women's University in Seoul who works for a foreign company and who spoke to Quartz on the condition of anonymity.

The satire and humour culminated in the creation of a Megalian dictionary as well as the parody of a popular South Korean comic targeted at young children learning basic classical Chinese characters. (All the characters are reinterpretations of the letter 男, which means 'man'.) Popular Megalian vocabulary and expressions include references to social problems caused by South Korean men as well as inversions of derogatory terms used by men on sites such as Ilbe:

1. Chanel lipstick: mocks the kimchi girl concept, a derogatory term used by men to refer to women who buy brand goods.

2. Papa: refers to South Korean men who have had extramarital affairs in South and Southeast Asian countries and abandoned their spouses once a child was born.

3. Blue \& Green Ilbe: reference to Facebook and Naver, both of which have demonstrated intolerant attitudes towards feminist comments while supporting misogynistic ones.
4. Schroedinger's South Korean Man: refers to a study which reported that approximately $58 \%$ of South Korean men have purchased sexual services; 5 . Dead Older Sister: refers to the selective abortion of female foetuses commonly practiced in South Korea up until the 1990s (in the belief that a son is more important than a daughter).

Although men are the main target of Megalia's mirroring techniques and retorts, women receive criticism as well. These women - dubbed 'corseted' (after the restraining fashion device) or 'Penis Emeritus' are, however seen as a product of the male-dominated society, who must break free from the injustices of patriarchy by individual will (and by joining Megalia, of course). It should be noted that almost all South Korean women are understood as having undergone a 'corseted' phase at some time in their life, as it is a social norm implemented on even the most feminist children.

The movement does not stop at simply mocking misogyny. It has backed several feminist campaigns including the crowd funding of adverts in Seoul's public transport system denouncing pornographic 'hidden cam' videos; endorsing support for and encouraging individual donations be made to New Political Alliance Democracy politician Jin Sunmee, who is leading a campaign to shut down Soranet, a South Korean porn hub associated with brokering underage prostitution and sharing videos of illegal nature. (Jin's office received a total of 10 million $\mathrm{KRW} / 9,000 € / 10,000 \$$ in the 24 hours following the upload of a post calling Megalians to donate. The site has worked extensively on exposing Soranet, South Korea's biggest pornographic website (over a million users are currently registered) and whose claim to fame lies on its ability to keep avoiding legal consequences by constantly changing domains names and servers, effectively placing it outside the jurisdiction of South Korean law [9].

The new wave of an online feminist movement that emerged in 2015 created women-only communities that enabled South Korean women to share their personal experiences as women and to reach the conclusion that in order to reject femininity and sexual objectification of women; they needed to take off the corset collectively. Awareness was manifested by encouraging other women to reject beauty practice and display their own tal-corset practice online and offline. The Korean word "tal" means "taking off (clothes)" or "breaking away from (something)" and corset represents sexist social customs, especially beauty practices, that are imposed on women. Participants in this movement usually cut their long hair short and stop wearing makeup and dresses, but degrees of participation vary depending on the individual. There is no data on exactly how many women are participating in this movement. Still, according to one survey, 56.3 percent of South Korean women in their 20s support it (Korean Women's Development Institute, 2018). The movement is bringing about many unprecedented social changes in South Korea. Year-on-year purchases of cosmetics, hair products, and other beauty products by South Korean women in their 20s significantly declined between 2016 and 2018. Expenditures on plastic surgery that had been consistently growing beforehand, declined 
by 64.6 billion won ( $\$ 58.3$ USD). There also emerged new clothing brands such as Fuse Seoul that focus on producing and selling items that are sold as genderless, quality clothing for women. There exists both a book and an academic article written in Korean that valuably describes the movement and its theoretical underpinnings. Minkyung Lee, in her recent book, Talcorset: An Imagination That Has Arrived (2019), offered insights gained from interviews with 17 movement participants. She stresses that the tal-corset movement is "the arena where feminist knowledge accumulated since 2015 is deployed and generated" [10]. She argues, this movement has been created through criticism against the trend of understanding body and appearance. She identifies the core purpose of this movement - escaping normative femininity imposed on women by quitting beauty practices. The tal-corset movement emerged as the answer against societal pressures on women's bodies and appearances that are universally witnessed around the world and in South Korea as well. South Korea is particularly well known for its meticulous, high-end beauty regimens - represented in the famous "10-step Korean skincare regimen" - and advanced technologies of cosmetic surgeries, being called "the plastic surgery capital" in one article. The term K-beauty came into public use within the last 10 years, referring to "Korea's global influence on aesthetics and cosmetics". K-beauty is associated with the Hallyu (Korean Wave), the global popularity of South Korean culture, and has resulted in a drastic increase in the export of Korean beauty products to other Asian countries and the west and a boom in plastic surgery tourism to Korea. The beauty industry's growth signifies the increase in social pressure on women's appearances in Korea, which seems contradictory to the rise of women's enhanced access to higher education and the job market. Statistics show that $31 \%$ of South Korean women in their 20 s have gone through plastic surgeries [11].

Discussions on the corset continued throughout 2016, but when it came to whether to actually "take it off", women's opinions varied. Some argued that no one should tell women what to do or not to do, or that women can, in some cases, do beauty practice for selfsatisfaction. Some women defended untraditional makeup applications, such as bold Smokey eye-makeup, by some women as a rebellious act against social norms that dictate women to look docile. R. Kim, who documented and analyzed this debate in an article, sees this as a group process of coming to a consensus that meanings of individuals' practices should be interpreted in the context of social structure and its influences [12]. Women stressed that wearing makeup originates from women's low social status and powerlessness in a patriarchal society, some saying that in equal societies, today's makeup would be regarded as film-like special effects because women would be no longer expected to put on makeup. In 2017 at Womad, the most radical women-only online community derived from Megalia, discussions on how to take off the corset started in earnest. B-Wave protest for abortion rights was organized by Womad and other women's online communities, which started in late 2016 and continued until 2019. It was the period when the abortion ban was lifted through a Constitutional Court ruling. And women had an opportunity to meet other women who have taken off the corset face to face.

In May 2018, South Korea witnessed the largest women's rally against male violence named The Courage to Be Uncomfortable. Spy-cam had already been a serious issue in South Korea. There had been reports on spy-cam videos and pictures being illegally posted online. Women had made complaints numerous times, failing to solicit serious actions from the government or the police. However, when a woman illegally filmed a male nude model, the police swiftly took action and arrested her. This double standard of the police investigation enraged women who had witnessed police inaction in cases with female victims over the years. In response, anonymous women organized a rally against the crimes of secret filming. The first rally - to the surprise of the public, the police, and the organizing team - brought 12,000 women to Seoul's streets. Afterward, this women-only rally was held almost every month, ending in December at the sixth rally with 350,000 accumulated participants in total. Chartered buses arrived at the rally with women from the southern half of the Korean peninsula. The women-only policy was so strict that even male reporters were not allowed inside the rally barricades [13]. The sheer number of participants and the fact that it was organized entirely by anonymous, average women online shocked the nation. The tal-corset movement was no longer an online campaign with limited numbers of anonymous women participating. It was now a social phenomenon and gained substantial media attention nationwide and overseas. Movement participants say that beauty practices are a marker of women's inferior social status and the mechanism that renders women dolls - turning women into things and commodities - and serves women's sexual objectification [14].

Women-only online communities such as Megalia and Womad provided Korean women with space where they could share their common experiences of oppression regarding their bodies and appearance. Through debates and discussions among women on what constitutes the corset, women countered the argument that beauty practices are an individual woman's choice and can be feminist. In response, they stressed the social aspects and impacts of beauty practices and posited that it originates from women's low social status and powerlessness in a patriarchal society. As women experience what it is like to live free of the corset their newly gained insights on how beauty practices oppress women are being actively shared online, including other Asian countries, leading other women to re-examine their own beauty practices.

The next movement called $\mathrm{Me}$ Too has expanded tremendously in just a few months in South Korea putting far behind China and Japan mostly thanks to a fortunate timing. There were two quite similar cases of sexual harassment where E. Lee is considered \#Me Too's pioneer and J. Seo became the face of the 
movement in South Korea. J. Seo's story was revealed at a time when feminism in South Korea was finally started to be seen as a tool for equality and justice, but most of all, as a subject worth making headlines and 8'oclok news, not an easy accomplishment in a male-dominated society. Because unlike the $\mathrm{Me}$ Too movement in the U.S which is mostly represented by celebrities, Me Too in South Korea started with the testimony of a regular citizen. Just like any Korean woman, Seo was a regular employee of an organization with an abusive patriarchal system, just like any Korean woman she had a husband to whom she was too afraid to talk, fearing she would burden him, just like any Korean woman she was too afraid to speak her truth. Following J. Seo's testimony, men and even women from all lines of business saw their career taken to the ground by women who had gained courage thanks to J. Seo's powerful words. Shortly after J. Seo's testimony, a powerful politician, former presidential candidate $\mathrm{H}$. Ahn was at the center of a sexual scandal that forced him to back down from his function as governor of South Chungcheong Province even though the court had acquitted him from Kim's rape allegations. An inadmissible Judicial decision according to feminist groups who quickly gathered on the streets to ask for a retrial [15]. J. Kim's accusation against $\mathrm{H}$. Ahn is the most high profile to date but other public figures quickly found themselves tangled in new sexual crime allegations. The literature world was particularly affected by Me Too in South Korea and revealed a dark truth in the literary circle: well-known artists have been using their influence to get sexual "services" from young writers who had no choice but to comply to see their work be published. The scandal "led to his poems being removed from school textbooks and a library space established by the Seoul Metropolitan Government in his name was also closed down." [16]. In a matter of significant historical importance, the Me Too movement in South Korea witnessed the long-awaited apology for sexual crimes committed by the Korean army during the still-controversial pro-democracy Gwangju Uprising of May 1980. Indeed, 38 years ago, Gwangju citizens rose against the martial law that took place under Dictator Chun Doo Hwan and the movement was violently repressed by the military. Today talking about this dark period is still very difficult for the government, and officials still have difficulties calling it a "massacre" (even if it obviously was) because that would force the government to confess to crimes that they previously said they had never committed. Therefore, when Defense Minister Jeong Kyeong apologized on television on November 7, 2018 in front of the all nation for the crimes committed by the army to innocent victims (women who were not even part of the uprising were also raped in their homes or taken to military garrison. The Ministry of Defense and from the National Human Rights Commission discovered 17 other victims of similar crimes. The Defense Minister and Prime Minister apologized a week after the report of the investigation team came out [17]. The Me Too movement opened up the discussion on sexual harassment accusations 'credibility. When women report sexual crimes that happened a long time in the past, the police (and the media in the case of public figures' revelations) tend to delegitimize women's testimonies. Victim blaming was at the center of women's silence. Indeed, one reason that stopped women from reporting their assault was the fear of not being heard and being actually turned into criminals. When women in South Korea wish to report a sexual crime, the remarks they would get from the police would be "How can you have been raped by your boyfriend?", "It's not rape if you went to the hotel with him.", "You shouldn't have worn a skirt" and other stereotypical remarks nourished by an international rape culture that never seems to lose momentum. Investigations are therefore conducted by doubting victims' statements and rarely by investigating the perpetrator [16].

Having your cries for help ignored and disregarded does not turn you into a criminal. However, the South Korean Criminal Act will. Indeed, as it turns out, the law itself is the enemy of violent crime victims in South Korea. No wonder South Korean victims of violent crimes are reluctant to report, by staying silent they are actually protecting themselves from being sued for defamation and false accusation, a crime punishable by two years in prison [16]. J. Seo's revelation did not just inspire women to report their stories to witness the fall of powerful men. After all, Me Too's core ambition is to inspire every woman to speak their truth and be liberated from their shame and put it back "where it belongs, on the perpetrators". In South Korea, women started to surf on the Me Too movement vague to change the unfair environments in which they are living in, in real life, as well as online.

\section{Conclusion}

The Korean peninsula has always had its own unique culture and community. At the beginning of statehood formation and the first states' existence women had equal rights with men in almost all spheres. As in any other society, early periods of state development are characterized by mainly matriarchal relationships. Women according to those times laws were allowed to reign the kingdoms and they successfully met the challenges. Confucianism and territory invasions provoking wars resulted in weakening woman's social status and strengthening man's social status as a defender and breadwinner.

According to Confucianism canons, Yin was associated with negative, passive, female principle in nature which obeyed Yang that is positive, active, male principle in nature. Thus, during centuries a woman was absolutely dependent on father, her husband and son. In general, a woman's prerogative was keeping households, bringing up children and being a good wife. However, only the nobles followed the Confucianism principles to the full extent. In peasant families, the woman's position was low, but keeping households and finances allowed her to have influence on her husband and have authority.

After Japanese invasion, the Korean women experienced some changes in working and social activities. They actively participated in industrial 
development, which gave them an opportunity to move freely and interact with males not thinking of being punished. But on the other hand, sometimes Korean women were kidnapped for sexual slavery as comfort women.

In spite of the westernization factors such as industrialization, modernization, and globalization the Confucianism engraved in the systems of values. Therefore, the social structure and cultural norms did not transform as fast as the economy of the country. Firstly, education was an additional advantage for a successful marriage, but later women were acquainted with feminist movements at universities that made them realize their self-esteem, uniqueness, the importance of education and employment. Striving for the job, income and independence became the main goal for a great number of Korean women.

Historically women used to face hardships and still they continue suffering from discrimination at work. Male employees are more preferable than females for the following reasons: marriage and childbirth. Moreover, the lack of proper childcare and irregular working hours prevent women from returning to workplace.

Generally, women's rights are either ignored or violated in all spheres of life. Sexual harassment cases remain silent and when males are sentenced, the punishment is not severe or even the accused is acquitted. The struggle for gender equality has been lasting for more than 70 years. Traditional patriarchal mentality deeply rooted in the society and has an impact on many aspects starting from private life to work. In perspective, the changes of Korean culture basis will be challenging and long-lasting.

\section{References}

1. M. J. Seth A History of Korea: From Antiquity to the Present (Lanham: Rowman \& Littlefield, 2011)

2. N.N. Kim, E.A. Khokhlova, Evolution of the social status of women in Korea: from traditional to modern society. Vostok, 3, 106-122 (2017)

3. W. Lee, H. Lee, M. Chang Yesterday and today of women's literature (Taehaksa, 2003)

4. M. Kim A study on women's consciousness in Gyubanggasa (Sungkyul University, 2006)

5. S. Lee Korean women in modern history (Kukhak Archive, 2014)

6. A.N. Lankov Gender in Korean (Russian Journal, 2003)

7. J. Joo Statistical Handbook. Women in Korea 2014 (Korean Women's Development Institute, 2015)

8. M. Park, S. Yoo, Y. Baek Perception of Feminists and the \#Metoo Movement: An Empirical Investigation of the Subtle and Implicit Gender Discrimination in the Workplace. Asian Communication Research, 17(2), 10-40 (2020)

9. H. Lee A Critical Study of Identity Politics Based on the Category 'Biological Woman' in the Digital Era: How Young Korean Women Became Transgender Exclusive Radical Feminists. Journal of Asian Sociology, 49(4), 425-448 (2020)
10. M. Lee Tal-corset: An Imagination That Has Arrived (Hankyoreh Publishing House, 2019).

11. H. Park Throwing off the Corset: A Contemporary owing off the Corset: A Contemporary History of the Beauty $y$ of the Beauty. Dignity: A Journal of Analysis of Exploitation and Violence, 5(3), 1-17 (2020)

12. R. Kim Postfeminism and Megalia. Korean Association of Feminist Philosophers Annual Conference Materials, 1, 11-113 (2018)

13. J. Kuk, H. Park, C. Norma Radical feminism paves the way for a resurgent South Korean women's movement (Feminist Current, 2018)

14. S. Kim Analysis of Gender Conflict Reports Appearing in Korean Newspapers After the \#MeToo Movement. Media and Personal Rights, 5(1), 95-139 (2019)

15. J. Jo The Contentiousness of Korean Women's Movement: From the Perspectives of Strategic Action Fields Theory and Practice Theory. Economy and Society, 123, 110-154 (2019)

16. Y. Kim The Emergence of "Megalian" Sites and "Mirroring" Strategies. The Current Online Women"s Movement. Ewha Womans University: Asian Women's Studies Center Conference Materials, 1, 57-60 (2017).

17. H. Lee A Critical Study of Identity Politics Based on the Category 'Biological Woman' in the Digital Era: How Young Korean Women Became Transgender Exclusive Radical Feminists. Journal of Asian Sociology, 49(4), 425-448 (2020) 